\title{
The comparation of comprehensive developments between children with large vestibular aqueduct syndrome and children without large vestibular aqueduct syndrome
}

\author{
Yanhong $\mathrm{Li}^{1}$, Yang Yang ${ }^{2}$, Wanxia Zhang ${ }^{1}$, Jihang Sun ${ }^{1}$, Bing $\mathrm{Liu}^{2}$, Min $\mathrm{Chen}^{3}$, Wei $\mathrm{Liu}^{3}$, \\ Bei $\mathrm{Li}^{1}$, Yi Zhou ${ }^{1}$, Shanshan Liu ${ }^{1}$, Xiaoxu Wang ${ }^{1}$, Shilan $\mathrm{Li}^{1}$, Jie Zhang ${ }^{3}$, and Xin $\mathrm{Ni}^{4}$ \\ ${ }^{1}$ Beijing Childrens Hospital, Capital Medical University, National Center for Childrens \\ Health \\ ${ }^{2}$ Beijing Children's Hospital \\ ${ }^{3}$ Capital Medical University \\ ${ }^{4}$ Capital Medical University Affiliated Beijing Children's Hospital
}

May 28, 2020

\begin{abstract}
Abstract Objective: To compare the comprehensive developments between children with large vestibular aqueduct syndrome (LVAS) and children without LVAS and investigate the risk factors for developments of LVAS children. Design: A retrospective propensity score matching analysis. Setting: Beijing Children's Hospital, Capital Medical University, National Center for Children's Health, Beijing, China. Method: 70 children with LVAS (41 boys, median of 28.50 months, range 6-72 months, hearing threshold: $82.54 \pm 12.58 \mathrm{~dB} \mathrm{nHL}$ ) and 70 gender-, age-, and auditory- matched overall children were recruited as LVAS and non-LVAS group, respectively. The developments of children were assessed by Gesell development schedules. Then the overall development and sub-development results were compared between the two groups. Regression analyses were used to assess the association between potential risk factors and developments of LVAS subjects. Results: Compared with normal developmental metrics, LVAS children and non-LVAS children both had developmental delay (both $\mathrm{P}<.001$ ), which occurred not only in verbal but also in non-verbal aspects (all $\mathrm{P}<.05$ ) except gross motor in non-LVAS subjects. Whereas, the deaf children of two groups had the similar performance including all sub-developments (all $\mathrm{P}>.05$ ). For the developments of LVAS children, the age of intervention was risk factor $(\mathrm{B}<0, \mathrm{P}<.05)$ and the developments of children older than 12 months was worse than those of children younger than 12 months $(\mathrm{P}<.05)$. Conclusion: Children with LVAS had the equal developmental level in comparison with children with same hearing impairments. Age of diagnosis was the risk factor for developments of LVAS children and the obvious delay of developments stared from 12 months.
\end{abstract}

\section{Key points}

- Deaf children had developmental delay, which occurred not only in verbal but also in non-verbal aspects.

- Children with LVAS had the equal developmental level in comparison with children with same hearing impairments.

- The obvious delay of developments stared from 12 months. thus, early intervention was advocated.

\section{1 | INTRODUCTION}

Enlarged vestibular aqueduct was a common kind of cochlear malformation in the temporal bone, which could induce hearing loss(1). Large vestibular aqueduct syndrome(LVAS) could be diagnosed with the classical hearing loss and a diameter $>1.5 \mathrm{~mm}$ at the midpoint of vestibular aqueduct according to the valvassori 
criterion(1,2). So far, LVAS has been increasingly accepted as the most common cause of congenital progressive sensorineural hearing loss in early childhood(1).

Apart from hearing loss, vestibular dysfunction has been reported associated with $\operatorname{LVAS}(3,4)$. About $87 \%$ of LVAS patients marked vestibular weakness exhibited by vestibular function tests in Berrettini's study and $89 \%$ of children with LVAS had at least one abnormal vestibular test results in Christina's reports $(5,6)$. Disequilibrium or vertigo as the typically vestibular symptoms were frequently appeared in LVAS patients $(1,7,8)$. In a retrospective study, vestibular symptoms (imbalance, vertigo, and/or motor delay) were approximately $46 \%$ and $48 \%$ in adult and pediatric patients with LVAS, respectively(9). Delayed ambulation and poor coordination were also reported in children with $\operatorname{LVAS}(8,10,11)$.

In the early stages of life, auditory input and communication were essential for cognition, behavior and social development(12-14). Developmental delay has been reported in children with hearing loss(14). For the patients with LVAS, as a special group of hearing loss with the characteristics of both hearing impairments and vestibular problems, we were used to paying them special attention in the clinical practice. In addition, the great body balance ability and skilled movement were important prerequisite for the child to interact with the external world to promote outstanding and all-round development (15-18). Yet, would vestibular disorders of LVAS children affect their motor development? were their comprehensive development levels worse than other deaf children? And would the factor of LVAS extra affect the developments of children? The above questions should be addressed in order to answer clinicians' and parents' doubts and give clinical guidance.

However, until to now, little study has been devoted to evaluated the development of children with LVAS particularly. In the present study, firstly, we investigated the comprehensive developments in children with LVAS and without LVAS separately, then compared their performance, and lastly analyzed the risk factors for developments of children with LVAS.

\section{2 | METHODS}

\section{1 | Study Design}

The present study was a retrospective cross-sectional study based on reviewing medical records of deaf children.

\section{2 | Participants}

645 children diagnosed with bilateral severe or profound sensorineural hearing loss in the Removed for Blind Peer Review were recruited in this study. Children were excluded if they had: 1) unable to completed the examination or evaluation; and 2) evidence of major secondary disabilities such as white matter diseases, nervous system disease, physical disability. Accordingly, 500 children were selected and all they completed auditory evaluation, CT scan of the temporal bone and developmental evaluation.

The CT scan was measured by the same specialized radiologist and the vestibular aqueduct, inner structure and internal auditory canal were paid special attention. The vestibular aqueduct was regarded as enlarged when midpoint diameter of vestibular aqueduct was $>1.5 \mathrm{~mm}$ in the axial view in a computed tomography scan (2). LVAS could be diagnosed when enlarged vestibular aqueduct was a separate anomaly and those combined with other inner ear malformations were excluded in this study. Representative examples of CT are shown in FIGURE 1.

According to the results of $\mathrm{CT}$ scan, 70 children diagnosed with isolated enlarged vestibular aqueduct were recruited as LVAS group. Among the remaining subjects without enlarged vestibular aqueduct, we used propensity matched analysis (PSM), matching the factors of gender, age and hearing threshold, at the ration of 1:1, to screen the candidate for non-LVAS subjects. Finally, 70 gender-, age-, and auditory- matched children were recruited as non-LVAS group.

\section{3-Data Collection}


The following data: gender, age (namely time to evaluate developments and the time to perform intervention), results of auditory, and results of Gesell were collected. TABLE 1 summarizes the demographic characteristics of the sample.

\subsection{1-Auditory Evaluation}

Comprehensive audiological evaluations were performed by trained professional staffs in our hearing center. Behavior audiometry was obtained with TDH-39P earphones (Interacoustics, AD229e) with the maximum output of $120 \mathrm{~dB}$ HL in the frequency of $500-4000 \mathrm{~Hz}$ and $110 \mathrm{~dB} \mathrm{HL}$ in the frequency of 250 and $8000 \mathrm{~Hz}$ bilaterally. Auditory steady-state response (ASSR) was obtained with TDH-39P earphones (Interacoustics, Eclipse) with the maximum output of $100 \mathrm{~dB}$ nHL bilaterally. Better ear hearing threshold was calculated for the thresholds of $500,1000,2000$, and $4000 \mathrm{~Hz}$, with a value of $5 \mathrm{~dB}$ over the limit at the frequency used as the calculation for no response thresholds(19). The difference between binaural hearing was calculated by the results of ASSR. If the difference was no more than $10 \mathrm{~dB}$ nHL, we defined it symmetry of binaural hearing; if it was more than $10 \mathrm{~dB}$ nHL, we thought it asymmetry(20).

\subsection{2 - Gesell Developmental Schedule Evaluation}

Certified clinical care physicians with expertise in working with deaf children administered developmental assessments to the study participants. The Gesell Developmental Schedule was a test on development of young children, which has been adopted and used in China for many years (21). It's used to diagnosis developmental and intelligence problems in children with objective criteria. The test consists of the five domains mentioned below:1. Gross motor such as sitting, walking, and jumping. 2. Fine motor such as eye hand coordination, ability to use small objects. 3. Adaptability such as reaction to moving objects or stimulation. 4. Language such as hearing, comprehension and expressive language capabilities. 5. Social skill such as interactions with people, ability to meet individual needs(22). The physicians selected the most appropriate test item of the Gesell development schedule for the child depending on their ages. By ascertaining whether or not the children were displaying the appropriate behavior for the age, an individual's developmental quotient (DQ) was calculated(22). According to the DQ, the developmental level can be graded into normal (more than 85 score), suspicious (76-85 score), mild neurological damage (55-75 score), moderate (40-54 score), severe (25-39 score) and very severe (less than 25 score) neurological damage $(22,23)$. Overall DQ and above five domains' DQ were adopted in this study and the above grading criteria were applied for all domain's development.

\section{4-Statistical Analysis}

The statistical analyses were performed using SPSS for Windows, version 22 (SPSS Inc, Chicago, IL, USA). The selection of subjects for non-LVAS group was performed by PSM method by matching the gender, age and hearing threshold at the ratio of 1:1. Continuous variables were expressed as the mean $\pm \mathrm{SD}$ or median (IQR) and categorical values were shown in the form of $\mathrm{n}(\%)$. For continuous variables, one-sample T-test, single-sample T-test, and ANOVA were used for normally distributed data and Mann-Whitney U test for non-normally distributed data. For categorical variables, chi square test and Fisher's exact test were used. Multivariate linear regression was performed to assess the relative contributions of corresponding variables to Gesell developments. $p<.05$ was considered statistically significant.

\section{3-RESULTS}

Finally, the LVAS group was composed of 70 children (boys, $58.57 \%$ ) with a median age of 28.50 months (range 6-72 months) (TABLE 1). As TABLE 1 shown that the hearing thresholds of ASSR and behavior audiometry were both belong to the profound hearing loss. The difference between binaural hearing was 13.57+-13.27 dB nHL with 54.29\% of symmetric binaural hearing rate. 70 gender-, age-, and auditorymatched children were recruited as non-LVAS group. As TABLE 1 shown that, there was no significant difference in gender $(P=.396)$, age $(P=.959)$, and auditory level (all $P>.05$ ) between the two groups.

Compared with the normal developmental criteria of 85 score in Gesell schedule, LVAS children and nonLVAS children both had developmental delay (TABLE 1, FIGURE 2). For LVAS children, the delay occurred 
in full-dimensional developments including gross motor, fine motor, adaptability, language, and social skill (all $P<.05)$ (FIGURE2). Whereas, for non-LVAS group, the delay didn't occurre in gross motor $(P=.199)$ (FIGURE 2).

Dividing the development results into four gradings (as shown in TABLE 2), for the above two groups, in terms of overall developments, majority of children were both distributed in mild neurological damage, similar distributions were found in the sub-developments of fine motor, language, adaptability, and social skill. Whereas, in gross motor, majority of children had the near-normal developments. The specific and detailed distribution rates were shown in TABLE 2. According to the above results, the language development was the worst, followed by social skills, adaptability, and fine motor, whereas gross motor was the best (TABLE 1-2, FIGURE 2).

Then, the developments were compared between the LVAS and non-LVAS groups. There was no difference in developments score including all sub-dimensional developments (all $P>.05$ ) (TABLE1, FIGURE 3) and similar results were found in the grading of developmental level (all $P>.05$ ) (TABLE 2). Although the difference results in gross motor in comparison with normal criteria, there was no significant difference between the two groups $(P=.673)$ (TABLE1, FIGURE 3 ).

Subsequently, the multivariate linear regression was performed to assess the relative contributions of corresponding variables to developments of LVAS children. The results showed that only age was the related factors to overall development $(B=-.253, P<.05)$ including sub-developments of gross motor, adaptability and social skill (all $B<0$, all $P<.05$ ) (TABLE 3). In order to explore the effect of age on the developments, LVAS subjects were divided into three groups: 6-12 months, 12-36 months and 36-72 months. Developmental scores of these three groups were provided in TABLE 4. Compared among the three age groups, significant differences were found in overall development $(P=.001)$ including sub-developments of adaptability, language and social skill $($ all $P<.05)$ but not in gross and fine motor (all $P>.05)$. We further made multiple comparisons in any two age groups. In gross and fine motor, there appeared significant difference in 6-12 months' and 12-36 months' group (all $P<.05$ ). In addition, compared with 6-12 months' group, the overall development in 12-36 months and 12-36 months' group had lower developmental scores $(P=.022, P=.003$, respectively), whereas, there was no significant difference between 12-36 months and 12-36 months' group $(P=.205)$. Similar results appeared in fine motor and adaptability (all $P<.05)$ (TABLE 4$)$.

\section{5 -DISCUSSION}

In clinical practice, children with LVAS always were such a group attracting our special care and attention, not only because of fluctuated hearing level, but also balance problems $(3,4)$. While, were there any differences in development level between LVAS subjects and children without LVAS? In order to solve the problem, we selected the specific two groups: children with LVAS and without LVAS but with the same hearing impairment, and compared the performance between the two groups, particularly discussing motor development in-depth.

Our study showed developmental retardation both in LVAS children and non-LVAS children. The retardation not only occurred in verbal development but also in non-verbal developments. Through the grading the developments, we found that the majority of children in this study had mild neurological damage. Of all subdevelopments, language developed worst and motor developed best. According to the results, developments of deaf children were worthy attention. Of note, the children in our study were the group with sever or profound hearing loss. Thus the developments in our study could not represent the whole performance of the group with hearing impairments, because the hearing level was associated with the developments revealed in previous research (24-26).

In previous literatures, delayed ambulation and poor coordination in LVAS children were reported $(8,10,11)$, which was consistent with our above findings. Prior to foregoing study, we evaluated more comprehensively including the gross motor such as sitting, walking and balance ability, and fine motor such as grabbing, pitching and coordination ability. In this study, compared with normal developmental criteria, LVAS children had developmental delay in gross motor, while non-LVAS children had the normal performance in gross motor. 
For the children with LVAS, a special group of hearing impairment, were their developmental level different from the other deaf children? To addressed the question, we compared the performance between the two groups and didn't found any significant difference including gross motor.

Although vestibular weakness have been marked in LVAS patients in previous study $(3,4)$, while motor retardation and disbalance of LVAS children in our study couldn't be concluded caused by vestibular disorder. According to our study, we could only describe such a phenomenon and couldn't conclude whether the vestibular dysfunction induced by LVAS has effects on development, of which the reasons could be summarized as follows. Firstly, the progress of hearing loss in LVAS patients was fluctuate(27), whereas the hearing thresholds of LVAS children in our study tend to their worst hearing level because they were candidate to cochlear implantation in our hospital. So, the hearing threshold couldn't represent the real average auditory level of LVAS children. Secondly, the age of hearing loss occurring, the duration of disease, and the usage of hearing aids, which might affect the developments, weren't normalized. Last but not least, although the LVAS patients were with high rates of vestibular dysfunction, the children with abnormal vestibular test results might not appear vestibular symptoms (8). In addition, balance ability were affected not only by vestibular consciousness but also by vision and proprioception(28). When one of them was damaged, the other functions would form compensation(29). Therefore, longitudinal follow-up study, vestibular tests, more evaluation specially for motor and balance should be adopted to address these issues.

In the clinical practice, regardless whether the vestibular dysfunction caused by LVAS had additional effects on developments, the phenomenon that there was no difference in developments between the two above groups was a great news for us. If so, we didn't pay extra attention to the developments in LVAS, compared with the other deaf children. Meanwhile, we could focus on the prevention to hearing deterioration in LVAS children and the search of good intervention methods after hearing impairments occurred.

Our study also found that age of intervention was the negative related factors for developments except fine motor. Thus, we further compared the developments among the different age group and found that the delay appearance infancy (6-12 months) to toddler (12-36 months) stage, whereas the developmental levels of the toddler and preschool (36-72 months) stages were no obvious difference. So, we could say that the delay started from the 1-year-old, which suggesting that the intervention should be performed before 1- year-old. Until now, hearing aids and cochlear implantation have been effective approach for increasing auditory perception(1,30,31). According to previous literature that intervention as soon as possible could improve the prognosis of hearing-impaired children(32,33). Moreover, children with LVAS undergoing cochlear implantation did well audiometrically and functionally as other deaf children without LVAS(34,35).

Considering the variety of hearing performance in LVAS children, we paid particular attention to the difference between binaural hearing. Of the LVAS subjects in our study, the mean difference between binaural hearing was more than $10 \mathrm{~dB}$ nHL with more than half of asymmetric hearing loss rates. Individuals with asymmetric sensorineural hearing loss have reported discomfort in daily living, both audiologically and psychosocially due to poor localization of sound and poor speech recognition in noise(36-38). whether would the asymmetric hearing loss affect the development of children especially the motor development? Then, we include the symmetry of the binaural hearing as a potential related factor. Through the analysis, we found that no matter the value of difference between binaural hearing or the symmetry couldn't affect the developments of LVAS children, including the motor development. Owing the children in our study were all with sever or profound hearing loss, it's possible that the influence from the symmetry was covered up by the effects from auditory deprivation

As potential limitation we have stressed in the article, this study was a cross-sectional study and vestibular function wasn't been evaluated in this study. So, whether vestibular function affected development of children couldn't be deduced. In addition, the age of hearing loss occurring and diagnosis, the duration of disease, and the usage of hearing aids, which might be the important factors for developments weren't into use in this study. Longitudinal follow-up study, professional evaluation specially for motor, balance vestibular tests, and vestibular function, and fully integrated information, should be adopted to address these issues. Of note, both objective and subjective evaluation on vestibular function were difficult to perform on young children, 
especially on deaf children. While, some scale such as Gesell development schedule adopted in this study was an effective and feasible method to evaluate performance of deaf children, which was further beneficial to formulate intervention strategy of cochlear implantation and rehabilitation strategy.

\section{5 - CONCLUSIONS}

In conclusion, this study provides evidence that children with severe or profound hearing loss could have comprehensive developmental delay. The developmental delay occurred not only in verbal but also nonverbal aspects. Although with developmental delay, children with LVAS had the equal developmental level in comparison with children with same hearing impairments. According to our results, whether the vestibular dysfunction induced by LVAS had effects on developments including motor developments couldn't be concluded. Longitudinal follow-up study and vestibular tests should be adopted to further address these issues. In addition, we found that age of intervention was the risk factor for developments of LVAS children. As the age of intervention was delayed, the delay in the development domains seemed worse and the obvious delay of developments stared from 12 months-old. Therefore, early diagnosis and intervention was proposed.

\section{ACKNOWLEDGEMENTS}

The author thank care center and hearing center in our hospital for their cooperation in gathering developmental and audio logical records.

\section{CONFLICT OF INTEREST}

There are no conflicts of interest.

\section{REFERENCES}

1. Gopen Q, Zhou G, Whittemore K, et al. Enlarged vestibular aqueduct: review of controversial aspects. Laryngoscope 2011;121:1971-8.

2. Deep NL, Carlson ML, Weindling SM, et al. Diagnosing Large Vestibular Aqueduct: Radiological Review of High-Resolution CT Versus High-Resolution Volumetric MRI. Otol Neurotol 2017;38:948-55.

3. Greinwald J, DeAlarcon A, Cohen A, et al. Significance of unilateral enlarged vestibular aqueduct. Laryngoscope 2013;123:1537-46.

4. Jung J, Suh MJ, Kim SH. Discrepancies between video head impulse and caloric tests in patients with enlarged vestibular aqueduct.Laryngoscope 2017;127:921-6.

5. Yang CJ, Lavender V, Meinzen-Derr JK, et al. Vestibular pathology in children with enlarged vestibular aqueduct. Laryngoscope2016;126:2344-50.

6. Berrettini S, Forli F, Bogazzi F, et al. Large vestibular aqueduct syndrome: audiological, radiological, clinical, and genetic features.American Journal of Otolaryngology 2005;26:363-71.

7. Song JJ, Hong SK, Lee SY, et al. Vestibular Manifestations in Subjects With Enlarged Vestibular Aqueduct. Otol Neurotol2018;39:461-7.

8. Zalewski CK, Chien WW, King KA, et al. Vestibular Dysfunction in Patients with Enlarged Vestibular Aqueduct. Otolaryngol Head Neck Surg 2015;153:257-62.

9. Grimmer JF, Hedlund G. Vestibular symptoms in children with enlarged vestibular aqueduct anomaly. International Journal of Pediatric Otorhinolaryngology 2007;71:275-82.

10. Noguchi Y, Fukuda S, Fukushima K, et al. A nationwide study on enlargement of the vestibular aqueduct in Japan. Auris Nasus Larynx 2017;44:33-9.

11. Zhou YJ, Wu YZ, Cong N, et al. Contrasting results of tests of peripheral vestibular function in patients with bilateral large vestibular aqueduct syndrome. Clin Neurophysiol 2017;128:1513-8. 
12. Phillips J, Wiley S, Barnard $\mathrm{H}$, et al. Comparison of two nonverbal intelligence tests among children who are deaf or hard-of-hearing. Research in developmental disabilities 2014;35:463-71.

13. Meinzen-Derr J, Wiley S, Grether S, et al. Functional communication of children who are deaf or hard-of-hearing. Journal of developmental and behavioral pediatrics : JDBP 2014;35:197-206.

14. Purcell PL, Shinn JR, Davis GE, et al. Children with unilateral hearing loss may have lower intelligence quotient scores: A meta-analysis. Laryngoscope 2016;126:746-54.

15. Horn DL, Pisoni DB, Miyamoto RT. Divergence of fine and gross motor skills in prelingually deaf children: implications for cochlear implantation. Laryngoscope 2006;116:1500-6.

16. Conway CM, Karpicke J, Anaya EM, et al. Nonverbal cognition in deaf children following cochlear implantation: motor sequencing disturbances mediate language delays. Developmental neuropsychology 2011;36:237-54.

17. Bigler D, Burke K, Laureano N, et al. Assessment and Treatment of Behavioral Disorders in Children with Hearing Loss: A Systematic Review.Otolaryngol Head Neck Surg 2019;160:36-48.

18. Vukkadala N, Perez D, Cabala S, et al. Linguistic and behavioral performance of bilingual children with hearing loss. International journal of pediatric otorhinolaryngology 2018;112:34-8.

19. Brown RF, Hullar TE, Cadieux JH, et al. Residual hearing preservation after pediatric cochlear implantation. Otol Neurotol2010;31:1221-6.

20. Seong J, Yang SK, Pilkeun Jang P, et al. Clinical Factors Influencing the Trial and Purchase of Bilateral Microphones with Contralateral Routing of Signal in Patients with Asymmetric Sensorineural Hearing Loss. JOURNAL OF AUDIOLOGY AND OTOLOGY2020;24:29-34.

21. Marques. RC, Dorea. JG, Bernardi. JVE, et al. Prenatal and postnatal mercury exposure, breastfeeding and neurodevelopment during the first 5 years 2009:- 134-41.

22. Gesell A. Monthly increments of development in infancy. Journal of Genetic Psychology 1925;32:203-8.

23. Yang Y, Haihong L, Jun Z, et al. The value of Gesell score in predicting the outcome of cochlear implantation in children. Eur Arch Otorhinolaryngol 2017;274:2757-63.

24. Wong CL, Ching TY, Leigh G, et al. Psychosocial development of 5-year-old children with hearing loss: Risks and protective factors. International journal of audiology 2018;57:81-92.

25. Leigh G, Ching TY, Crowe K, et al. Factors Affecting Psychosocial and Motor Development in 3-YearOld Children Who Are Deaf or Hard of Hearing. Journal of deaf studies and deaf education2015;20:331-42.

26. Melo RS, Lemos A, Raposo MCF, et al. Balance performance of children and adolescents with sensorineural hearing loss: Repercussions of hearing loss degrees and etiological factors. International journal of pediatric otorhinolaryngology 2018;110:16-21.

27. Zelikovich EI, Tropchina LV, Kurilenkov GV. Enlarged vestibular aqueduct syndrome: etiology, clinical features, diagnostics, and rehabilitation of the patients. Vestnik otorinolaringologii2015;80:46-50.

28. Chiba R, Takakusaki K, Ota J, et al. Human upright posture control models based on multisensory inputs; in fast and slow dynamics. Neuroscience Research 2016;104:96-104.

29. Appiah-Kubi KO, Wright WG. Vestibular training promotes adaptation of multisensory integration in postural control. Gait \& Posture2019;73:215-20.

30. Patel ND, Ascha MS, Manzoor NF, et al. Morphology and cochlear implantation in enlarged vestibular aqueduct. Am J Otolaryngol2018;39:657-63.

31. Asma A, Anouk H, Luc VH, et al. Therapeutic approach in managing patients with large vestibular aqueduct syndrome (LVAS).International journal of pediatric otorhinolaryngology2010;74:474-81. 
32. Alyami H, Soer M, Swanepoel A, et al. Deaf or hard of hearing children in Saudi Arabia: Status of early intervention services.International journal of pediatric otorhinolaryngology2016;86:142-9.

33. Moeller MP, Carr G, Seaver L, et al. Best practices in family-centered early intervention for children who are deaf or hard of hearing: an international consensus statement. Journal of deaf studies and deaf education 2013;18:429-45.

34. Lee KH, Lee J, Isaacson B, et al. Cochlear implantation in children with enlarged vestibular aqueduct. Laryngoscope 2010;120:1675-81.

35. Chen X, Liu B, Liu S, et al. The development of auditory skills in infants with isolated Large Vestibular Aqueduct Syndrome after cochlear implantation. International journal of pediatric otorhinolaryngology 2011;75:943-7.

36. Lucas. L, Katiri. R, Kitterick. PT. The psychological and social consequences of single-sided deafness in adulthood2018;57:21-30.

37. Tabasi M, Javadinia SA, Siadat SD, et al. Positional Vertigo and Unilateral Gradual Hearing Loss Following Sleeve Gastrectomy: A Case Report. Diabetes Metabolic Syndrome and Obesity-Targets and Therapy 2020;13:387-90.

38. Augustine AM, Chrysolyte SB, Thenmozhi K, et al. Assessment of Auditory and Psychosocial Handicap Associated with Unilateral Hearing Loss Among Indian Patients. Indian Journal of Otolaryngology and Head E Neck Surgery 2013;65:120-5.

\section{Hosted file}

figure-1. docx available at https://authorea.com/users/327098/articles/454783-the-comparationof-comprehensive-developments-between-children-with-large-vestibular-aqueduct-syndromeand-children-without-large-vestibular-aqueduct-syndrome

\section{Hosted file}

figure-2. docx available at https ://authorea.com/users/327098/articles/454783-the-comparationof-comprehensive-developments-between-children-with-large-vestibular-aqueduct-syndromeand-children-without-large-vestibular-aqueduct-syndrome

\section{Hosted file}

figure-3.docx available at https ://authorea.com/users/327098/articles/454783-the-comparationof-comprehensive-developments-between-children-with-large-vestibular-aqueduct-syndromeand-children-without-large-vestibular-aqueduct-syndrome

\section{Hosted file}

table-1.docx available at https://authorea.com/users/327098/articles/454783-the-comparationof-comprehensive-developments-between-children-with-large-vestibular-aqueduct-syndromeand-children-without-large-vestibular-aqueduct-syndrome

\section{Hosted file}

table-2.docx available at https://authorea.com/users/327098/articles/454783-the-comparationof-comprehensive-developments-between-children-with-large-vestibular-aqueduct-syndromeand-children-without-large-vestibular-aqueduct-syndrome

\section{Hosted file}

table-3.docx available at https://authorea.com/users/327098/articles/454783-the-comparationof-comprehensive-developments-between-children-with-large-vestibular-aqueduct-syndromeand-children-without-large-vestibular-aqueduct-syndrome 


\section{Hosted file}

table-4.docx available at https://authorea.com/users/327098/articles/454783-the-comparationof-comprehensive-developments-between-children-with-large-vestibular-aqueduct-syndromeand-children-without-large-vestibular-aqueduct-syndrome 